\title{
BIOG-BYWORD
}

\section{Application \\ of \\ Building \\ Material \\ Testing Technology}

\author{
Jing Sun* \\ Chongqing Energy College, Chongqing 402260, China \\ *Corresponding author: Jing Sun, 757809546@qq.com
}

\begin{abstract}
The article analyses the application of building material testing technology, concludes that though the application of building material testing technology, the quality of the material can be tested, and unqualified materials can be found in time, and removed from the construction, to prevent the impact of the construction effect, and ensure the quality of the construction project.
\end{abstract}

Keywords: Testing; Construction projects; Materials

Publication date: November 2021; Online publication: November 30, 2021

\section{Introduction}

Material is an important structure of the main part of the project. In order to ensure the quality of the main part of the project, the quality of construction materials needs to be guaranteed first. Through the application of building material testing technology, the quality of the material can be tested, and unqualified materials can be found in time, and removed from the construction, to prevent the impact of the construction effect, and ensure the quality of the construction project.

\section{The important role of building engineering material testing technology application}

Building materials are important substances in the construction of construction projects. In order to ensure the quality of construction projects, the quality control of materials needs to be done first. If there are problems in the quality of materials in the construction of construction projects, it is very easy to cause hidden dangers in the construction of construction projects, and even cause life risks, so it is necess ary to strengthen the detection of building materials.

\subsection{Improve the safety of construction projects}

Safety is the primary management goal in the construction of construction projects. Through the testing of construction materials, it is conducive to ensuring the safety of construction projects and effectively avoiding the mixing of inferior materials in construction that will affect the construction quality ${ }^{[1]}$. In order to promote the smooth development of construction projects, construction enterprises need to do a good job in the initial stage of construction, testing of materials, including the stability, safety and deflection of materials, to ensure that the strength and safety of construction materials can meet the requirements of engineering construction.

\subsection{Ensure the materials meet the construction requirements of the construction project}

In the construction of construction engineering, in order to ensure the waterproof, seismic, compressive and other effects of the project, a large number of prefabricated components need to be used, and if these 
prefabricated components do not meet the requirements of engineering construction, the quality of engineering construction will be affected, which is not conducive to the later use. Through the quality inspection of prefabricated components before construction, the problems existing in prefabricated components can be found in time, and the components can be replaced in time, so as to improve the overall quality of the project.

\subsection{Improve the durability of construction projects}

The application quality and application of materials in construction directly affect the service life of building materials. In engineering construction, the main body and most of the prefabricated components need to be exposed to the external environment for a long time, and be subjected to the weather for a long time, which will affect the service life. Therefore, it is necessary to test the durability of the prefabricated components before the construction of the construction project, so that the prefabricated components can meet the requirements of the building environment. Through the testing of construction materials in the construction of engineering projects, the overall cost of engineering construction can be reduced and the economy of the project can be improved.

\section{Application of Building Material Testing Technology \\ 3.1. Testing of cement materials}

With the development of construction industry, the application scope of cement materials is more and more extensive. In the construction of building engineering, cement material is not only a common material, but also a common material for engineering construction quality and service life. Cement is used most in the construction of reinforced concrete structures. If there are problems in the quality of cement materials, it will inevitably increase the safety risks of construction projects, which are not conducive to the quality control of construction projects and the safety management of personnel. In the test of cement materials for construction engineering, the standard of "General Portland Cement" is mainly adopted, and the test work is carried out in strict accordance with standards such as experiment, process and use method ${ }^{[2]}$. First of all, do a good job of on-site acceptance of materials, mainly on the cement package integrity inspection. At the same time, the strength grade, grade and stability of cement are tested. In order to ensure the quality of cement, it is also necessary to check the production date of cement and ensure that the date of cement is within three months. And the cement performance and indicators need to be checked, so that the cement can meet the standards and indicators. After the basic performance inspection, it can enter the construction site. In the process of testing, the qualification of the manufacturer and the quantity of cement should be tested to ensure that the sampling quantity and frequency of testing meet the standard requirements. For bagged cement, it is generally tested every 200 tons, and bulk cement is tested every 500 tons. In the sampling of cement, it is necessary to ensure the sampling of the same batch and different positions. The detection sample points of each batch shall be controlled at least 20, and the weight of mixed sampling shall be more than $12 \mathrm{~kg}$.

\subsection{Testing of sand and gravel materials}

Sand and gravel material is also an important part of building materials. Thus, the detection of sand and gravel materials is also necessary. In the process of sampling sand and stone, it is necessary to take random samples of materials in the sand and stone pile to ensure the uniformity of sampling. At the same time, in the process of sampling the sand pile, the surface layer of sand and gravel should be removed first and sampled at different locations. Sand and stone can be sampled separately. Eight samples are generally selected for the sampling of sand material, and 16 samples are generally selected for the sampling of stone material, and then mixed after the sampling is completed. In the screening process, if the test results are 
unqualified, it is necessary to increase the sampling times and reinspect the sand and stone materials. In addition, the materials can also be processed by four-point method. The specific operation is to place the sand and gravel sampling material on the flat plate and stir it evenly, form the material into a round cake shape with a paving thickness of about $20 \mathrm{~cm}$, and then divide it into four samples with similar quality for re mixing. In the inspection of sand and stone, it is necessary to carry out multiple tests and parallel tests combined with the requirements of building construction to ensure the quality of sand and stone.

\subsection{Testing of reinforcing steel materials}

Reinforcing steel material is equivalent to the skeleton of the main body of the building. In the process of reinforcing steel bar detection, the main aim is detecting the mechanical properties of steel bar. The specific detection process is as follows: First, material sampling should be carried out reasonably. Due to the special properties of reinforcing steel materials, there are certain differences with cement and sandstone in sampling. The sampling work shall be carried out in strict accordance with the reinforcing steels. First, a section of reinforcing steel with a length of 500 to $1000 \mathrm{~mm}$ shall be intercepted. Generally, 5 reinforcing steels shall be selected for interception in the sample extraction, and the key deviation of reinforcing steel shall be detected first. Second, carry out cold drawing test on the reinforcing steel, and conduct batch inspection on the reinforcing steel according to the national requirements for reinforcing steel products. The inspection quantity of reinforcing steel in the same batch needs to be controlled within 30 tons, and the diameter and grade of reinforcing steel must be the same. Third, inspect the quality of reinforcing steel, the types of reinforcing steel in reinforcing steel welding are different, and there will be some differences in welding methods. Current welding methods include arc welding, spot welding, butt welding and so on. It is necessary to combine the specific welding with corresponding operation requirements for detection ${ }^{[3]}$. For example, if the spot welding is used, the rationality of the welding project needs to be tested. Spot welding testing is carried out strictly according to the operational requirements. The length of the spot inspection steel bar is generally controlled in 500 to $650 \mathrm{~mm}$, and it can be tested by means of shear test and stretching test.

\subsection{Testing of concrete strength}

The concrete strength test during construction is also an important test content in the pouring of construction engineering. During the test, random samples can be taken in the pouring area. According to the mechanical characteristics and standards of concrete, the cube specimen with a size of generally $150 \mathrm{~mm}$ square can be selected for curing the concrete block. Each group can select 3 specimens, The mixture of each group of test pieces shall be sampled from the same batch of concrete, and the curing must be carried out in combination with specific curing conditions and standards during the curing process. In the curing of concrete test blocks, if the standard curing method is adopted, the curing time needs to reach 28 days. If the same conditions are used for curing, it shall be calculated according to the cumulative curing age of the daily average temperature. The cumulative total temperature shall reach $600^{\circ} \mathrm{C}$, and the curing age shall reach more than 14 days, but less than 60 days. In the compressive strength test of concrete test block, the corresponding test block experiment scheme can be formulated, the appearance of the test block can be checked, the temperature, humidity and date of the test block can be recorded. After the press is cleared, the test block can be placed in the press plate, and the constant speed test can be carried out. Until the failure of the specimen, the computer automatically collects data and records the maximum failure load of the specimen.

\section{Conclusion}

To sum up, the application of material test and detection technology in building engineering construction 
is conducive to the detection of building material quality, which is particularly important for the development of China's construction industry. From the application of testing technology of engineering building materials in China, each material has its own testing method. However, some testing methods are not scientific and normative, so it is necessary to strengthen the improvement of testing technology standards, effectively reduce the error probability of testing technology, and rationally select testing technology in combination with the needs of different engineering buildings to improve the efficiency of construction engineering and ensure the standardization of testing technology. Lay the foundation for the improvement of construction engineering quality through the testing of materials, so as to promote the better development of the construction industry.

\section{Disclosure statement}

The author declares no conflict of interest.

\section{References}

[1] Xu W, 2021, Discussion on the Testing Technology of Building Engineering Materials. Brick \& Tile World, (1): 59.

[2] Li S, 2021, Application Analysis of Testing and Detection Technology for Building Engineering Materials. Brick \& Tile World, (1): 94.

[3] Wang Y, 2020, Discussion on Test and Testing Technology of Building Engineering Materials. Value Engineering, 39 (6): 181-182. 